\title{
Predicting Thermal Performance of Different Roof Systems by Using Decision Tree Method
}

\begin{abstract}
A. U. Weerasuriya
Abstract:

This paper describes the use of decision tree method to predict thermal performance of several roof systems under different climate conditions. The decision tree method is a data mining technique which has competitive advantages over other methods such as simple and clear procedure, easy to understand without having rigorous mathematical and computational knowledge, etc. Results of 80 energy simulation cases were used to demonstrate the applicability of this method in building energy simulation. These 80 simulation cases are based on five locations in five different climate zones, eight different roof systems, and two extreme climate conditions; warmest and coldest in a year of a particular location. The modelled decision tree has prediction accuracy of $84 \%$ on training data and $100 \%$ on test data. Addition to that, decision tree automatically ranked the best selection of roof system under prevailing climate conditions. The predicted values shown in each classified data subsets can be used as a reference with an accuracy of $6 \%$ to predict the indoor room temperature with the use of a particular roof system. Finally, derived decision rules and simplified guidelines from constructed decision tree are also provided in a tabular format for non-engineer users.
\end{abstract}

Keywords: Decision tree method, Energy simulation, Roof Systems, Thermal performance

\section{Introduction}

The significant percentage of total energy consumption of a building is used to restore the acceptable occupant thermal comfort level [1, 2]. The direct and indirect heat transfer of building components are the main factors affecting the occupant thermal comfort by increasing the indoor temperature. Among other common building components, roof itself generates significant heat loading due to its vast surface area and the orientation which is directly facing to the sky. Therefore a designer can maintain acceptable indoor thermal environment for occupants by selecting a suitable roof system and carefully controlling its thermal properties.

Energy simulation techniques have been widely used to assess the thermal performance of the whole or part of a building [3, 4]. However, its accuracy on predicting energy demand of an occupied building is lower than that for an onoccupied building due to the uncertainty of latent heat generation from human bodies and electrical appliances. There are several drawbacks of energy simulation methods such as steep learning curve to operate software, the necessity to perform separate simulation for every case-study, more suited to evaluate designed buildings rather than those in early design stage, use of simplified methods and limited numbers of factors considered for analysis. Therefore, other techniques which are capable of overcoming these shortcomings have been adapted to model building energy demand.

The traditional regression analysis method and Artificial Neural Network (ANN) method are two of the most popular techniques successfully used by researchers in the past [3]. The simple and efficient regression analysis method is based on statistical analysis and regression equation which is able to combine effect of various climate variables with building physics in order to predict building energy demand $[5,6,7]$. However, complicated nature of regression equation demands that the user has a good mathematical background. The structure of ANN is similar to biological neural networks. It is able to build complex relationships with different factors in the building energy simulation process and thus, get more accurate output $[8,9,10,11,12]$. Nevertheless an ANN model cannot be understood and interpreted easily as it operates as a "black box" within the analysis process.

Decision tree method is one of the data mining techniques that has been used in scientific and medical fields $[13,14,15.16,17]$ to make decisions based on the consideration of several inputs simultaneously. The flow chart like structure allows understanding and interpreting the analysis easily even for a user without specific mathematical knowledge.

Eng .A.U. Weerasuriya, B.Sc.Eng(Hons), M.Sc. (Moratuwa), AMIE(Sri Lanka), PhD candidate, Department of Civil and Environmental Engineering, Hong Kong University of Science and Technology, Hong Kong. 
However, the use of the decision tree method in building energy simulation is very sparse. Yu et al.[18] demonstrated the use of decision tree method in building energy simulation in detail analysis by predicting energy use intensity of houses in Japan.Tso and Yau [19] compared the accuracy of the decision tree method with regression analysis and ANN method and found that its accuracy was almost the same as other two methods.

\section{Decision tree method}

The decision tree model is a logical model which predicts the value of a target variable by using the values of a set of predictor variables. Both categorical and numerical attributes can be used as either target or predictor variables unless the use of categorical variables are preferred to numerical variables in terms of accuracy. However, the selection of attributes for the split tests is more significant in a decision tree model as it follows a greedy algorithm. The decision tree algorithm iteratively divides the domain by selecting split attributes that can best separate the target class values. Therefore, the accuracy of the output is heavily dependent on the quality of selection of split attributes. The concept of entropy is used to measure the quality of a split attribute. The quality is by means of the purity of a partitioning in decision tree nodes. Equation (1) shows the method to calculate entropy value for a domain with two types of variables HIGH and LOW by using binary split test at node $D_{i}$.

$$
\text { Entropy }\left(D_{i}\right)=-\left(\frac{{ }^{n} H I G H}{T N} \log _{2} \frac{{ }^{n} H I G H}{T N}+\frac{{ }^{n} L O W}{T N} \log _{2} \frac{{ }^{n} L O W}{T N}\right) \text {. }
$$

Where, ${ }^{n} \mathrm{HIGH}$ : the number of 'HIGH' variables in node $D_{i}$ and ${ }^{n} L O W$ : the number of 'LOW' variables in node $D_{i} ; T N$ : the total number of 'HIGH' and 'LOW' variables in node $D_{i}$.

The entropy value varies in between 0 and 1 for any split test. The value 0 indicates the pure split while 1 shows the 50/50 division of a binary split test.

After the split test at node $D_{i}$, the domain is divided in to two sub domains, can be referred to as $\mathrm{DS}_{1}$ and $\mathrm{DS}_{2}$ with number of record $s m$ and $n$ in respective sub domains. The efficiency of a split test can be evaluted by entropy difference of the parent domain and children domains as shown in Equation (2). This entropy difference is called "information gain (InfoGain)" of the $i^{\text {th }}$ node.
$\operatorname{InfoGain}=\operatorname{Entropy}\left(D_{i}\right)-\operatorname{Entropy}\left(D S_{1}\right.$ and $\left.D S_{2}\right)$

Entropy $\left(D S_{1}\right.$ and $\left.D S_{2}\right)$ is the weighted sum of

the entropies of subsets $\mathrm{DS}_{1}$ and $\mathrm{DS}_{2}$ calculated according to Equation (3)

$$
\text { Entropy }\left(D S_{1} \text { and } \begin{array}{rl}
\left.D S_{2}\right) & =\frac{m}{m+n} \operatorname{Entropy}\left(D S_{1}\right) \\
& +\frac{n}{m+n} \operatorname{Entropy}\left(D S_{2}\right)
\end{array}\right.
$$

The entropy values of $D S_{1}$ and $D S_{2}$ are calculated as Equation (1).

However, information gain is a biased parameter for domains with many data sets. To avoid this deficiency, information gain is normalized with size of the domain so called the Gain Ratio. The gain ratio is calculated as shown in Equation (4)

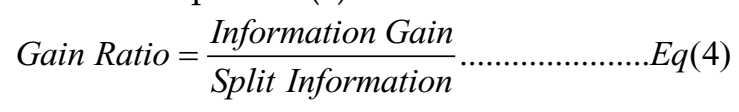

Where,

$$
\begin{aligned}
\text { Split Information } & =\frac{m}{m+n} \log _{2} \frac{m}{m+n} \\
& +\frac{n}{m+n} \log _{2} \frac{n}{m+n} .
\end{aligned}
$$

The split attribute with the highest gain ratio would be used for the split test at $i^{\text {th }}$ node.

\section{Energy simulations of different roof systems}

\subsection{Climate data and building physical data}

Both input data sets of climate and building physical properties should include wide range of data in order to construct a successful decision tree. The following methodology was adopted to collect necessary input data for decision tree analysis in the absence of field measurement data.

Five locations in different climate zones were selected to represent different prevailing climate condition. These five locations are Colombo (Sri Lanka), Athens (Greece), Hong Kong (China), Riyadh (Saudi Arabia), and Chicago (United States) to represent tropical monsoonal, , Mediterranean climate, humid subtropical climate, equatorial dessert hot arid and hot summer continental climate zones respectively. Both warmest and coldest months of these locations were selected to evaluate thermal performance of the roof systems under extreme climate conditions. Mean monthly temperature and the humidity values together with sunshine hours in both warmest and coldest months of these locations are shown in Table 1.These climate factors are also used as input data for energy simulations. 
Table 1- Climate data of 5 locations

\begin{tabular}{|c|c|c|c|c|c|c|c|}
\hline \multirow[t]{2}{*}{ Climate zone } & \multirow[t]{2}{*}{ Location } & \multirow[t]{2}{*}{ Month } & \multirow[t]{2}{*}{$\begin{array}{l}\text { Sunshine } \\
\text { hours }\end{array}$} & \multicolumn{2}{|c|}{$\begin{array}{l}\text { Mean daily } \\
\text { temperature }\left({ }^{\circ} \mathrm{C}\right)\end{array}$} & \multicolumn{2}{|c|}{$\begin{array}{l}\text { Mean relative } \\
\text { humidity(\%) }\end{array}$} \\
\hline & & & & Max & Mini & Max & Mini \\
\hline \multirow{2}{*}{$\begin{array}{l}\text { Mediterranean } \\
\text { climate }\end{array}$} & \multirow{2}{*}{$\begin{array}{l}\text { Athens } \\
\text { (Greece) }\end{array}$} & July & 12 & 31.8 & 22.8 & 42 & 59 \\
\hline & & January & 4 & 13.6 & 7 & 63 & 75 \\
\hline \multirow{2}{*}{$\begin{array}{l}\text { Hot summer } \\
\text { continental climate }\end{array}$} & \multirow{2}{*}{$\begin{array}{l}\text { Chicago } \\
\text { (United States) }\end{array}$} & July & 9 & 28 & 17 & 54 & 82 \\
\hline & & January & 3 & -1 & -10 & 66 & 77 \\
\hline \multirow{2}{*}{$\begin{array}{l}\text { Tropical } \\
\text { monsoonal }\end{array}$} & \multirow{2}{*}{$\begin{array}{l}\text { Colombo } \\
\text { (Sri Lanka) }\end{array}$} & April & 7.9 & 31.1 & 24.3 & 68 & 95 \\
\hline & & December & 6.9 & 29.8 & 22.4 & 61 & 91 \\
\hline \multirow{2}{*}{$\begin{array}{l}\text { Humid subtropical } \\
\text { climate }\end{array}$} & \multirow{2}{*}{$\begin{array}{l}\text { Hong Kong } \\
\text { (China) }\end{array}$} & July & 8 & 31 & 27 & 71 & 84 \\
\hline & & January & 5 & 19 & 14 & 64 & 75 \\
\hline \multirow{2}{*}{$\begin{array}{l}\text { Equatorial dessert } \\
\text { hot arid }\end{array}$} & \multirow{2}{*}{$\begin{array}{l}\text { Riyadh } \\
\text { (Saudi Arabia) }\end{array}$} & July & 10 & 42 & 28 & 8 & 16 \\
\hline & & January & 8 & 19 & 8 & 32 & 60 \\
\hline
\end{tabular}

A two-storey house with total floor area of 99 $\mathrm{m}^{2}$ was selected for the energy simulation modeling. This builiding is similar to the modelled building that was used by Halwathura and Jayasinghe [20]. Sloped and flat roof shapes were used for three basic roof types; concrete flat roof, calicut tile roof and asbestos sheet roof. Some modifications were introduced for these roofs such as a sloped ceiling for asesbestos sheet roof and calicut tile roof, insulate concrete roof, green roof and concrete roof with parapet walls for concrete roof slab. The insulated slab system is similar to model proposed by Halwathura and Jayasinghe $[21,22]$. The green roof has a $10 \mathrm{~cm}$ grass layer on top of the roof as proposed by Dareeju et al [23]. More details about roof systems used for this study are shown in Table 2.

Table 2 - Roof systmes use for energy simulations

\begin{tabular}{|l|l|}
\hline Roof system & Components (from top to bottom) \\
\hline Asbestos sheet & One layer of $6 \mathrm{~mm}$ thick fiber cement sheet \\
\hline Calicult tile & One layer of $20 \mathrm{~mm}$ thick fiber cement sheet \\
\hline Concrete roof & $20 \mathrm{~mm}$ cement rendering, $125 \mathrm{R} / \mathrm{C}$ slab, $10 \mathrm{~mm}$ sofit palster \\
\hline Asbestos sheet with a ceiling & $\begin{array}{l}\text { Fiber cement sheet, } 2 \mathrm{~mm} \mathrm{aluminium} \mathrm{foil,} \mathrm{25} \mathrm{mm} \\
\text { polyurethane, } 5 \mathrm{~mm} \text { flat asbestos sheet }\end{array}$ \\
\hline Calicut tile roof with a ceiling & $\begin{array}{l}\text { Calicut tile layer, } 2 \mathrm{~mm} \text { aluminium foil, } 25 \mathrm{~mm} \text { polyurethane, } \\
5 \mathrm{~mm} \text { flat asbestos sheet }\end{array}$ \\
\hline Insulated concrete roof slab & $\begin{array}{l}40 \mathrm{~mm} \text { cement rendering, 25 mm expanded cellular } \\
\text { polyethylene layer, } 125 \mathrm{~mm} \mathrm{R} / \mathrm{C} \text { slab, 10 mm soffit plaster }\end{array}$ \\
\hline Green roof & $\begin{array}{l}10 \mathrm{~mm} \text { thick grass layer, 25mm soil layer, } 125 \mathrm{~mm} \text { R/C slab, } \\
10 \mathrm{~mm} \text { soffit plaster }\end{array}$ \\
\hline $\begin{array}{l}\text { Concrete roof with parapet } \\
\text { walls at the perimeter }\end{array}$ & $\begin{array}{l}20 \mathrm{~mm} \text { cement rendering, 125 R/C slab, } 10 \mathrm{~mm} \text { sofit palster } \\
\text { surrounded by } 1 \mathrm{~m} \text { high parapet wall }\end{array}$ \\
\hline
\end{tabular}

3.2. DEROB-LTH Modelling 
DEROB-LTH was used as the energy simualation software for this study. It was used by previous researchers [20, 21, 23] and accuracy was evaluated with field measurements[20]. Two types of data inputs are needed for a DEROB simulation, one data set for climate data and other about the building model. The orientation of building is north-south direction and all windows are also in north and south directions only. The 225 $\mathrm{mm}$ thick cement plastered brick walls are at the perimeter and $115 \mathrm{~mm}$ plastered brick walls used as internal walls. Floor is made with 75 mm thick concrete with a tile paved surface. First floor slab is $125 \mathrm{~mm}$ thick and at the bottom side there is $15 \mathrm{~mm}$ thick soffit plaster and and upside is paved with ceramic tiles. There is a balcony at first floor level, which is protected by a shading device. All windows are wooden framed single glazed windows and doors are timber panelled type.

There are altogether 80 simulation cases ( 8 roof types $\times 5$ locations $\times 2$ months) used to build the decision tree. In every case, the indoor temperature of the upper floor volumes were extracted because those volumes are directly under influence of roof system rather than spaces in ground floor level.

\section{Preliminary analysis of data}

4.1. Analysis of monthly average temperature Outdoor air temperature is one of the main factors influencing occupant comfort level. The amount of variation of the outdoor temperature from the neural temperature would be a better measurement to determine required level of thermal performance of a roof system. Figure 1 shows the boxplot graph for montly average out door air temperature for the selected locations.

According to the Figure 1, Colombo has minimum temperature variation, which is minimum and maximum monthly temperature values are close to the annual average temperature. For other four locations larger deviations can be observed among average and highest and lowest temperatures. Thus the selection of two extreme temperature cases for this study can be justified. The annual average temperature is above $9^{\circ} \mathrm{C}$ for all five locations and that value is close to $20^{\circ} \mathrm{C}$ except for Chicago city. Only Chicago has the lowest temperature below the freezing point.

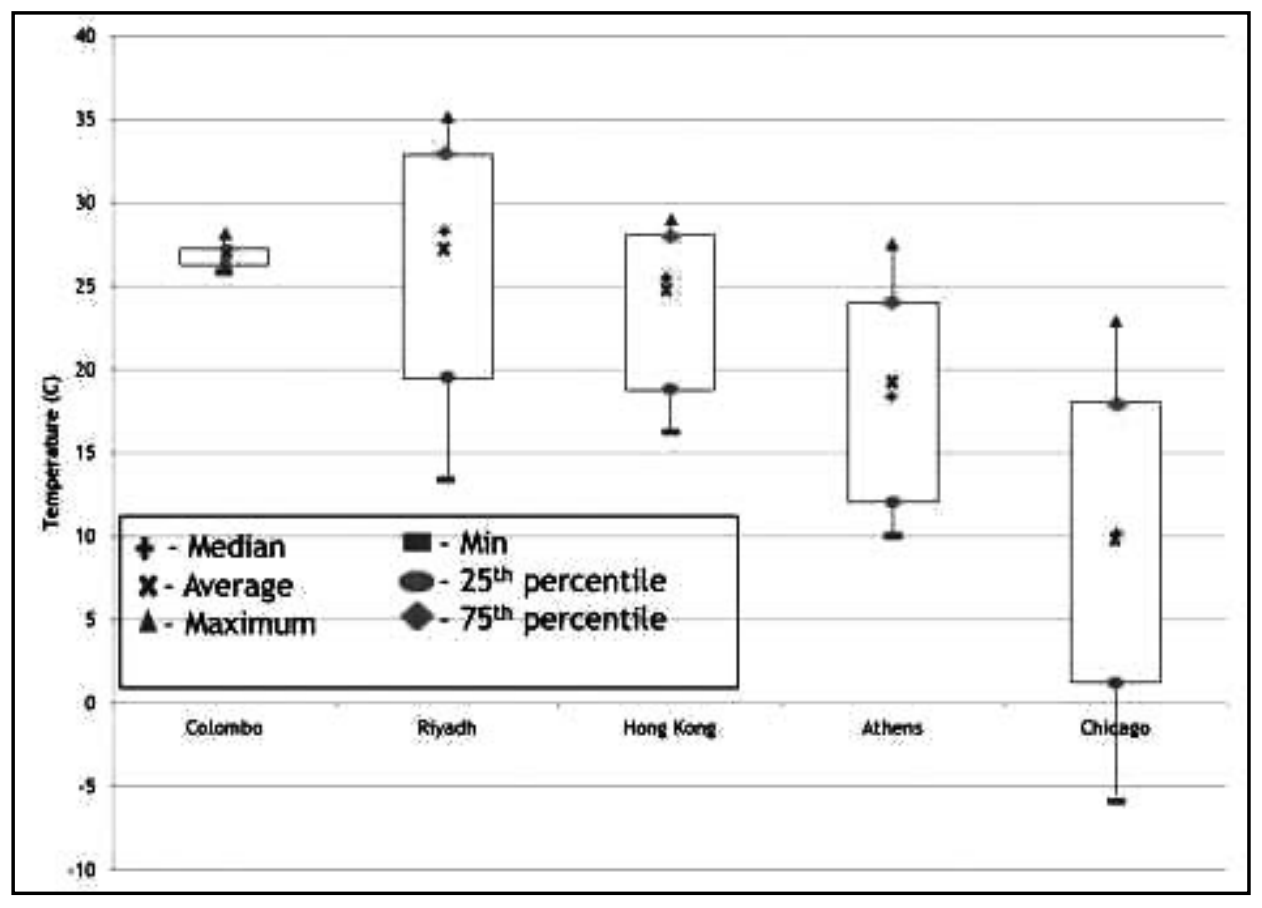

Figure 1 - Distribution of monthly average outdoor temperature 


\subsection{Selection of attributes for the decision tree.}

There are several climate and building physical factors affecting thermal performance of a roof. Some of these factors are numerical attributes such as tempeature, humidity and some of them are categorical attributes such as shape of the roof, roof covering material, etc. it is necessary to convert numerical attributes to categorical attributes to obtain a more accurate decision tree. For the simplicity, only binary categorical attributes were used for this study for an example temperature is simplified in to two categorical attributes" $\mathrm{HIGH}^{\prime \prime}$ temperature or "LOW" temperature. The annual average values of numerical attributes were used for the binary separation of those attributes The attributes used for constructing decision tree are listed in Table 3. It is necessary to have even distribution of categorical variables in each location to build an unbiased decision tree model. According to the Figure 2, the categorical distribution at each location has fairly even distribution, that percentage is varying between $25 \%$ to $47 \%$. In order to demonstrate the thermal performance of a roof system, normalised average indoor temperature was used as the prediction attribute in the decision tree. This value is calculated as Equation (5). The 'high difference' is defined as the normalised average indoor temperature value exceeds1.04 or 0.96 .

The advantage of this parameter is that it is directly combined with the outdoor temperature and thus easy to understand even by nonengineering user. It is also more convenient to use in heating/cooling load calculations as it enables the determination of indoor temperature implicitly.

Normalised Indoor temperature $=$

Average temperature of upper floor volumes

Monthly average temperature

Table 3 - Attributes used for the decision tree

\begin{tabular}{|l|l|l|}
\hline \multicolumn{1}{|c|}{ Attributes } & \multicolumn{1}{|c|}{ Splitting test } & \multicolumn{1}{c|}{ Remarks } \\
\hline Temperature & HIGH/LOW & Temperature greater than $20^{\circ} \mathrm{C}$ is high \\
\hline Humidity & HIGH/LOW & Humidity greater than $60 \%$ is high \\
\hline Shape & FLAT/SLOPED & Only apply to concrete slabs \\
\hline Insulation & WITH/WITHOUT & Ont \\
\hline Ceiling & WITH/WITHOUT & Apply only to asbestos and Calicut tile roof \\
\hline Parapet walls & WITH/WITOUT & $\begin{array}{l}\text { Indoor temperature normalized with the outdoor } \\
\text { temperature. If the difference is more than }( \pm 4 \%) \\
\text { then difference is high }\end{array}$ \\
\hline $\begin{array}{l}\text { Normalized } \\
\text { indoor }\end{array}$ & HIGH/LOW &
\end{tabular}

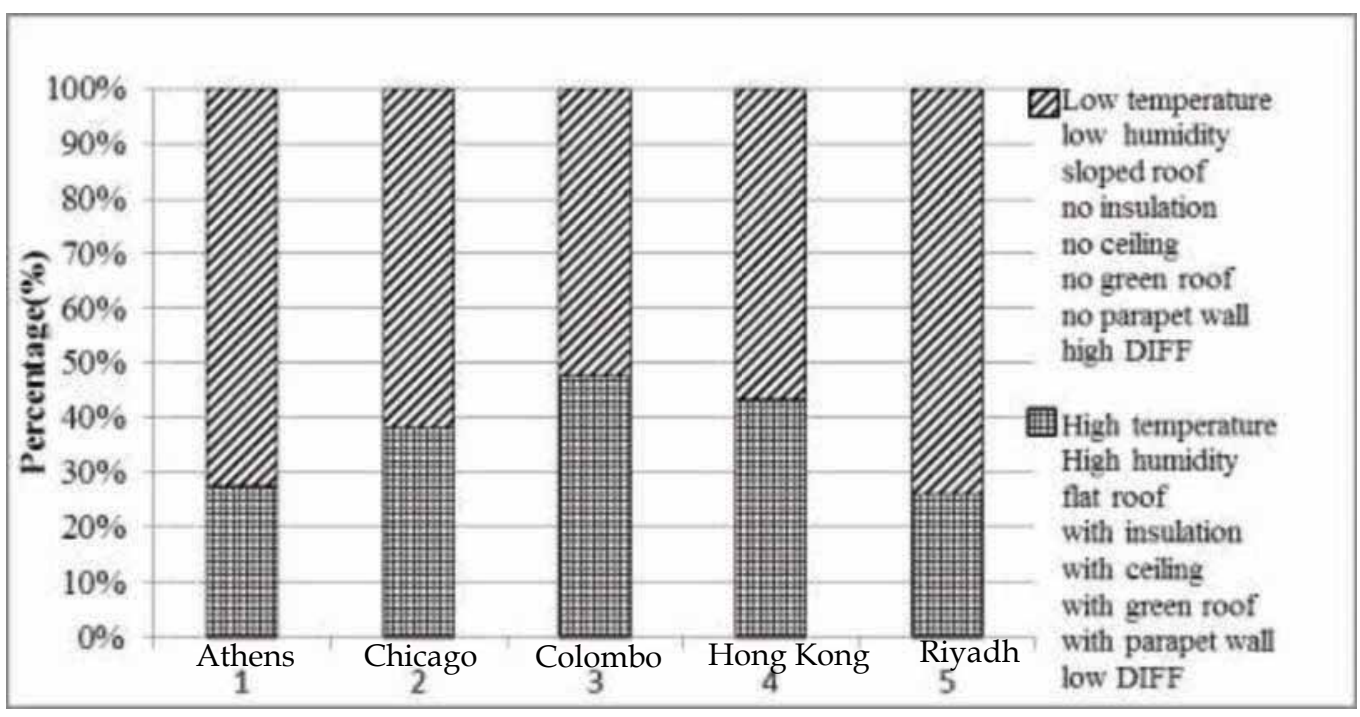

Figure 2 - Categorical distribution of attributes in 5 locations 
5.

\subsection{Generation of decision tree}

The steps of constructing a decision tree can be shown as Figure 3. There are two stages of the procedure named, learning and classification. In learning stage, first divide the whole data set in to two subsets called training and test data sets. In this study total 80 data sets were divided into two subsets such as 75 data sets for training and
Thus, it is a time consuming repetitive process. Therefore, an open source data mining software WEKA was used for this study. WEKA was originally developed by University Waikato, New Zealand and previously used by $\mathrm{Yu}$ et al[18] for a similar study. There are different decision tree algorithms within the WEKA. J48 algorithm was selected for this study by using trial and error method, which gaves the highest

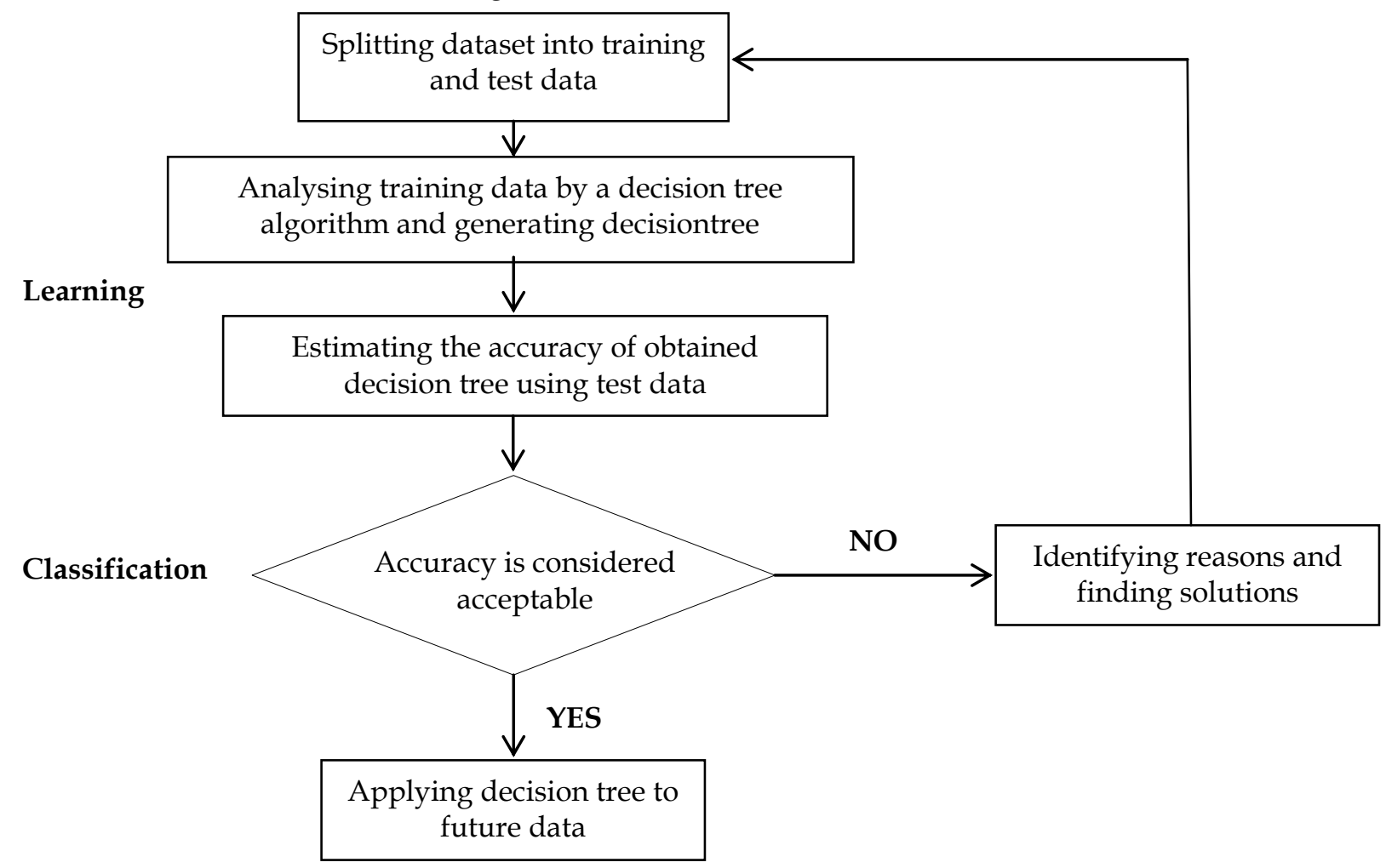

Figure 3 - Flow chart of making a decision tree (Yu et al. [18])

5 data sets for test. The decision tree is generated and its accuracy is calculated by analysing the training data set. In the classification stage, if the accuracy of the decision tree is acceptable it can be used for future projects. If the accuracy is not adequate, then it is necessary to identify the reasons and fix them and regenerate a new decision tree.

At each node it is necessary to calculate entropy of parent and children data sets, information gain, split information and gain ratio for selecting the split attribute. The same calculation prodcedure should be repeated at each node until one of the following criteria is met

1. All records in a partition share the same target class value.

2. There are no remaining predictor attributes that can be used to further split a partition.

3. There are no more records for a particular value of a predictor variable. accuracy for training data set. The generated decision tree is shown in Figure 4.

The generated decision tree has four levels and 15 nodes. Each node represents either a split test or a decision rule. The Root node and internal nodes show details of split test such as number of data sets and split attribute. Leaf nodes express the decision rules. However, leaf nodes with entropy value 0 are labled as LEAF and otherwise named as STOP. STOP nodes are resulted when there is no significant effects that can be obeserved on information gain ratio in further candidate spliting tests. In both LEAF and STOP nodes, there are information about number of data, calssification result, predicted normalised indoor temperature (NIT), and the lable LEAF or STOP. More details about nodes are shown in Figure 5.

The WEKA analysis report shows some information regarding accuracy of the constructed decision tree. According to the report that accuracy is $84 \%$. Though this 
accuracy is not very high it is acceptable compared to the low number of data sets used as the training set. Information regarding misclassification can be found from the confusion matrix as shown below.
The above matrix implies that 40 LOW NIT cases have 34 correct classifications with 6 missclassification instances.

There are 6 misclassification cases in HIGH. NIT cases among total 35 number cases 


\subsection{Evaluation of decision tree}

Before, using the constructed decision tree to predict thermal performance of roof systems in future projects it is necessary to assess its accuracy by using test data sets. In this study, only five data sets were randomly selected as test data sets due to limited number of available data. The five test data sets selected are shown in Table 4 with their properties. The predictions of the decision tree are listed in Table 5 with classification result and predicted NIT value.
The percentage error in predicted value and the actual NIT value is also shown.

All five test cases are correctly predicted by the decision tree. This prediction accuracy $100 \%$ is higher than accuracy $(84 \%)$ of decision tree. It is believed that this occurs due to limited numbers of test data sets used for evaluation. However, the maximum percentage error is much lower as 5.83 for the test data set, which indicates the better prediction ability of the decision tree.

Table 4 - Data used for the evaluation of the accuracy of decision tree

\begin{tabular}{|c|c|c|c|c|c|c|c|c|}
\hline & Case & 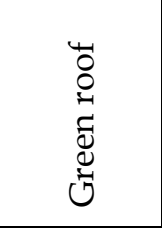 & 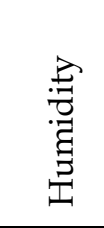 & $\stackrel{\infty}{:}$ & 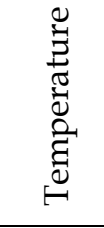 & 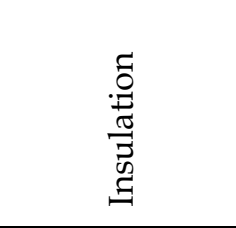 & 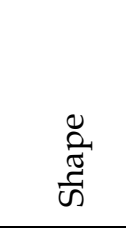 & 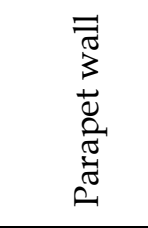 \\
\hline 1 & Flat roof & Nogreen & High & Without & High & No Insulation & Flat & NoPWall \\
\hline 2 & Clay Tile roof & Nogreen & High & Without & High & No Insulation & Sloped & NoPWall \\
\hline 3 & Flat roof & Nogreen & High & Without & Low & No Insulation & Flat & NoPWall \\
\hline 4 & Green roof & Green & Low & Without & Low & No Insulation & Flat & NoPWall \\
\hline 5 & $\begin{array}{l}\text { Asbestos roof } \\
\text { with ceiling }\end{array}$ & Nogreen & High & With & Low & No Insulation & Sloped & NoPWall \\
\hline
\end{tabular}

Table 5 - Summary of results of evaluation of the decision tree

\begin{tabular}{|l|l|l|l|l|l|l|}
\hline Case & Actual level & $\begin{array}{l}\text { Predicted } \\
\text { level }\end{array}$ & $\begin{array}{l}\text { Correct/ } \\
\text { Incorrect }\end{array}$ & $\begin{array}{l}\text { Actual } \\
\text { NIT }\end{array}$ & $\begin{array}{l}\text { Predicted } \\
\text { NIT }\end{array}$ & Error \\
\hline 1 & HIGH NIT & HIGH NIT & Correct & 1.123 & 1.062 & $5.43 \%$ \\
\hline 2 & HIGH NIT & HIGH NIT & Correct & 1.054 & 1.062 & $0.76 \%$ \\
\hline 3 & HIGH NIT & HIGH NIT & Correct & 0.947 & 0.953 & $0.63 \%$ \\
\hline 4 & LOW NIT & LOW NIT & Correct & 1.033 & 1.004 & $2.81 \%$ \\
\hline 5 & LOW NIT & LOW NIT & Correct & 1.032 & 1.018 & $1.36 \%$ \\
\hline
\end{tabular}

Another aspect of the decision tree is that each LEAF or STOP node represents a decision rule. The constructed decision tree has 8 LEAF and STOP nodes which can be used to derive 8 different decision rules. For an example, node 6 expresses that if roof is not a green roof and with high humidity level and roof with a ceiling then the normalised indoor temperature is low. All derived decision rules are listed in Table 6.

The priority order of selection of different roof system under high $\left(>20^{\circ} \mathrm{C}\right)$ and low $\left(<20^{\circ} \mathrm{C}\right)$ temperature is shown in Table 7 . The green roof is the first choice under both climate conditions suggests that it out performed other roof systems in any climate zone. Ceiling is also a better remedy to achieve acceptable indoor temperature in both high and low outdoor temperature conditions. However, insulated roof system only performs well under high out door temperature condition. The shape of the roof and use of parapet walls are only effective under low outdoor temperatures but yet their significance is less compared to use of green roof or installing a ceiling.

\section{Conclusion}

The decision tree method was used in this study to predict thermal performance of different roof systems in different climate zones. 80 test cases were simulated by using energy simulation software for a two-storey house. Eight different roof systems used in this study covers traditional roof systems such as asbestos roof sheet, Calicut tile roof, and 
concrete roof with some improvements such as sloped ceiling, green roof, insulated roof slab and roof slab protected with parapet walls. The total 80 numbers of data were divided into two and 75 data sets were used as the training data sets and balance five data sets were used as test data sets. Constructed decision tree has 15 nodes in seven levels. The accuracy of the decision tree is $84 \%$ for training data set and $100 \%$ for the test data set. There are eight decision rules, which can be derived from the decision tree. However, the accuracy of decision tree is limited by number of data set used for the study. It is also necessary to mention that there are some other parameters needed to consider doing an energy simulation such as accurate ventilation rate, internal latent heat gain from human bodies and electrical appliances which are not considered in this study. More consideration should be paid when interpreting numerical attributes due to results of splitting tests depend on the used threshold values. Thus, threshold values should be selected in a fair and rational manner.

Even the decision tree method leads accurate predictions on energy simulation results in this study it is recommended to use field measurements to verify its validity under different prevailing site conditions in future studies. It is also necessary to test applicability of this method to design more energy efficient buildings in different building categories such as commercial, public, apartment buildings, etc.

Table 6 - Derived decision rules from the decision tree

\begin{tabular}{|l|l|l|}
\hline & Node & Decision Rules \\
\hline 1 & 3 & If roof is GREEN then NIT is LOW \\
\hline 2 & 4 & If roof is NOT GREEN and HUMIDITY is HIGH then NIT is HIGH \\
\hline 3 & 6 & $\begin{array}{l}\text { If roof is NOT GREEN and HUMIDITY is HIGH and WITH A CEILING then NIT is } \\
\text { LOW }\end{array}$ \\
\hline 4 & 10 & $\begin{array}{l}\text { If roof is NOT GREEN and HUMIDITY is HIGH and WITHOUT A CEILING and } \\
\text { TEMPERATURE IS HIGH and WITHOUT AN INSULATED SLAB then NIT is HIGH }\end{array}$ \\
\hline 5 & 11 & $\begin{array}{l}\text { If roof is NOT GREEN and HUMIDITY is HIGH and WITHOUT A CEILING and } \\
\text { TEMPERATURE IS HIGH and WITH AN INSULATED SLAB then NIT is LOW }\end{array}$ \\
\hline 6 & 13 & $\begin{array}{l}\text { If roof is NOT GREEN and HUMIDITY is HIGH and WITHOUT A CEILING and } \\
\text { TEMPERATURE IS LOW and WITH A SLOPED ROOF then NIT is LOW }\end{array}$ \\
\hline 7 & 14 & $\begin{array}{l}\text { If roof is NOT GREEN and HUMIDITY is HIGH and WITHOUT A CEILING and } \\
\text { TEMPERATURE IS LOW and WITH A FLAT ROOF and WITH PARAPET WALLS } \\
\text { then NIT is LOW }\end{array}$ \\
\hline 8 & 15 & $\begin{array}{l}\text { If roof is NOT GREEN and HUMIDITY is HIGH and WITHOUT A CEILING and } \\
\text { TEMPERATURE IS LOW and WITH A FLAT ROOF and WITHOUT PARAPET } \\
\text { WALLS then NIT is HIGH }\end{array}$ \\
\hline
\end{tabular}

Table 7 - Selection of suitable roof system

\begin{tabular}{|l|c|c|c|c|}
\hline Potential factors & \multicolumn{2}{|l|}{ High temperature sites $\left(>20^{\circ} \mathrm{C}\right)$} & \multicolumn{2}{l|}{ Low temperature sites $\left(<20^{\circ} \mathrm{C}\right)$} \\
& Significant factor & Rank & Significant factor & Rank \\
\hline Green roof & $\sqrt{ }$ & 1 & $\sqrt{ }$ & 1 \\
\hline Ceiling & $\sqrt{ }$ & 2 & $\sqrt{ }$ & 2 \\
\hline Insulated slab & $\sqrt{ }$ & & $\sqrt{ }$ & 3 \\
\hline Shape & & & & 4 \\
\hline Parapet walls & & & $\sqrt{ }$ & \\
\hline
\end{tabular}




\section{Acknowledgement}

The author of this paper would like to express his gratitude towards Dr. Jack Chen from Department of Civil and Environmental Engineering, Hong Kong University of Science and Technology for his guidance given in throughout this study. The valuable advices given on DEROB-LTH modelling by Dr. R.U. Halwathura from Department of Civil Engineering, University of Moratuwa and Mr. B.S.S.S. Dareeju from Sapienza University, Rome are highly appreciated.

\section{References}

[1]. Annual energy reviews 2011, United States Energy Information Administration, available www.eia.gov/aer

[2]. Statistical year book for Asia and the Pacific 2011, United Nations economic and social commission for Asia and the Pacific, available

http://www.unescap.org/stat/data/syb2 011/II-Environment/Energy-supply-anduse.asp

[3]. Jebaraj, S., Iniyan, S., A review of energy models, Renewable and Sustainable Energy Reviews, 10, 2006, pp 281 - 311

[4]. Hong, T., Chou, S.k, Bong, T.Y., Building simulation: an overview of developments and information sources, Building and Environment, 35, 2000, pp 347 - 361

[5]. Catalina, T., Virgone, J., Blanco, E., Development and validation of regression models to predict monthly heating demand for residential buildings, Energy and Buildings, 40 (10), 2008, pp 1825-1832

[6]. Bentzen J, Engsted T. A revival of the autoregressive distributed lag model in estimating energy demand relationships. Energy,26, 2001, pp 45-55

[7]. Ghiaus, C., Experimental estimation of building energy performance by robust regression, Energy and Buildings, 38 (6), 2006, pp 582-587.

[8]. Magnier, L., Haghighat, F., Multi objective optimization of building design using genetic algorithm and artificial neural network, Building and Environment, 45, 2010, pp 739-746

[9]. Aydinalp M, Ismet U. V., Fung A.S., Modelling of the appliance, lighting and space-cooling energy consumptions in the residential sector using neural networks. Applied Energy, 71, 2002, pp 87-110

[10]. Kalogirou, S. A., Bojic, M., Artificial neural networks for the prediction of the energy consumption of a passive solar building, Energy, 25, 2000, pp 479 - 491

[11]. Kokasl, M. A., Ugursal, V. I., Comparison of neural network, conditional demand analysis, and engineering approaches for modelling end-use energy consumption in the residential sector, Applied Energy, 85, 2008, pp 271-296.

[12]. Zhang, J., Haghighat, F., Development of artificial neural network based heat convection for thermal simulation of large rectangular cross-sectional area earth-toearth heat exchanges, Energy and Buildings, 42 (4),2010, pp 435-440

[13]. El-Bakry, H. M., Hamada, M., New fast decision tree classifier for identifying protein coding regions, 35th International Symposium on Computer Architecture (ISCA 2008), June 21-25, 2008, Beijing, China, 489 -500

[14]. Fan, C.Y., Chang, P.C.,. Lin, J.J., Hsieh, J. C., A hybrid model combining case-based reasoning and fuzzy decision tree for medical data classification. Applied Soft Computing, 2011, pp 632-644

[15]. Eisenberg, J. N. S., Mckone, T. E., Decision tree method for the classification of chemical pollutants: incorporation of across-chemical variability and within chemical uncertainty, Environment Science Technology, 32, 1998, pp 3396 - 3404

[16]. Tung, K.Y., Huang, I.C., Chen, S.L., Shih, C. T., Mining the Generation Xers' job attitudes by artificial neural network and decision tree-empirical evidence in Taiwan, Expert Systems with Applications,29 (4), 2005, pp 783-794.

[17]. Wehenkel, L., Pavella, M., Decision tree approach to power systems security assessment, International Journal of Electrical Power \& Energy Systems,15, 1993, pp 13-36

[18]. Yu, Z., Haghighata, F., Fung, B.C.M., Yoshino, H., A decision tree method for building energy demand modelling, Energy and Buildings, 42, 2010, pp 16371646

[19]. Tso, G.K.F., Yau, K.K.W., Predicting electricity energy consumption: a comparison of regression analysis, decision tree and neural networks, Energy, 32 (9), 2007, pp 1761-1768

[20]. Halwatura R.U., Jayasinghe, M.T.R., Strategies for improved micro-climates in high-density residential developments in tropical climates, Energy for Sustainable Development,11( 4), 2007, pp 54-65 
[21]. Halwatura R.U., Jayasinghe, M.T.R., Thermal performance of insulated roof slabs in tropical climates, Energy and Buildings, 40, 2008, pp 1153-1160

[22]. Halwatura, R.U., Jayasinghe, M.T.R., Influence of insulated roof slabs on air conditioned spaces in tropical climatic conditions-A life cycle cost approach, Energy and Buildings, 2009, pp 678-686

[23]. Dareeju B.S.S.S, Meegahage J.N., Halwatura R.U., Influence of grass cover on flat reinforced concrete slabs in a tropical climate, International Conference on Sustainable Built Environment (ICSBE - 2010),2010, pp 469-479 